\title{
CONSTITUCION, DERECHO Y PRINCIPIOS PENALES
}

\author{
Victor Prado Saldarriaga $(*)$
}

\section{Introducción}

La Constitución de 1979 ha cumplido su primer decenio de vigencia. Durante este período sus claros propósitos humanistas y de democracia social han determinado importantes cambios en la estructura política, económica y cultural del país. Es más, en lo psicosocial podemos reconocer cómo la idiosincracia nacional se ha constitucionalizado, superando así la apatía cívica en que quedó sometida por doce años de dictadura militar. Todo esto, pues, permite un balance positivo: Nuestra Constitución en estos últimos 10 años ha cumplido con muchos de los objetivos que se resumen en su emotivo preámbulo.

Sin embargo, los efectos negativos de la violencia política así como los transtornos sociales ocasionados por la crisis económica, han motivado que también dentro de dicha década hayan transcurrido graves momentos de inestabilidad constitucional. En estas coyunturas, múltiples actos estatales han suscitado agudos conflictos de eficacia o de legitimidad material a los principios rectores de la Constitución. Y uno de esos ámbitos de contradicción entre las normas constitucionales y las decisiones políticas del Estado, ha sido el concerniente a la legislación penal.

Si bien es cierto que en 1981 el Ejecutivo sc preocupó scriamente por revisar el derecho penal producido durante el régi-

(*) Profesor de Derecho Penal y Política Criminal PUC y UNMSM. 
men castrense, a fin de adecuarlo a las premisas de la nueva Ley fundamental, las disposiciones penales de los años posteriores se fueron alejando de aquella primera intención. Surgiendo en cambio una vocación político criminal sobrecriminalizadora y autoritaria, que no ha dudado en trasgredir los límites que la Constitución establecía para el ejercicio legitimo del jus puniendi. Cabe señalar como ejemplos los sucesivos actos de demanda y debates sobre la pena de muerte y los tribunales militares para el juzgamiento de casos de terrorismo.

En una reciente investigación que realizamos sobre la producción de normas penales en el período 1979-1989, pudimos con preocupación constatar que más del $70 \%$ clel total de leyes promulgadas adolecían de problemas de constitucionalidad. Partiendo, pues, de esa tendencia hacia la inconstitucionalidad que sigue nuestro derecho punitivo, es que hemos optado por presentar algunas reflexiones sobre los contenidos formales y materiales de los principios constitucionales de regulación penal.

Estamos convencidos de que la exigencia de un sistema de control penal acorde al Estado Social y Democrático de Derecho. que postula nuestra Constitución, es también una vía válida y necesaria para superar la violencia que agobia a nuestra población. De otro lado, la consolidación de un modelo penal mínimo y garantista es también un medio importante de defender la estabilidad domocrática de un país. Pero en cambio si permitimos que el Estado de Derecho se convierta en un mero Estado de leyes, como infortunadamente suele ocurrir con las democracias latinoamericanas. estaremos creando desde el sistema penal una nueva fuente de intolerancia y de arbitrariedad donde la seguridad del ciudadano debe sucumbir ante la discutida "razón de Estado".

\section{Naturaleza y Función de los Principios Reguladores del Control Penal}

Una de las características del Estado liberal fue la elaboración de políticas dirigidas a limitar los canales de intervención del Control Penal en el desarrollo de las relaciones sociales. Ello era coherente con el rol de vigilante del libre mercado de trabajo y 
de la reproducción de capitales, que se otorgó al Estado en aquel período. Se trataba, pues, de frenar la omnipotencia del Estado absolutista, y que habría impedido el desarrollo del naciente capitalismo burgués.

Las ideas de igualdad y de libertad dieron al derecho penal un carácter formal menos cruel y agresivo que el que tuvo durante el feudalismo y la consolidación del Estado Absolutista. Además la legitimación del Control Penal, como un recurso necesario para el mantenimiento del contrato social, quebró todo posible rezago de "divinidad" o de confusión entre derecho penal y moral (1).

Con el transcurso de los siglos esos principios limitadores del control se han reforzado formalmente mediante su inclusión en las Constituciones y ante la constatación de los abusos cometidos por los regímenes totalitarios y autoritarios. Es más, muchos de esos principios son hoy también reconocidos y proclamados como derechos o garantías por las diferentes normas internacionales de promoción de los derechos humanos.

Los principios reguladores del Control Penal a los que nos referimos son los siguientes:

1. Principio de Legalidad.

2. Principio del Bien Jurídico Real.

3. Principio de Mínima Intervención.

4. Principio de Humanidad.

5. Principio de Culpabilidad.

6. Principio de Jurisdiccionalidad.

7. Principio de Proporcionalidad de las Sanciones.

En realidad, más que principios se les debería denominar políticas. Entendiendo el término política en sentido estricto; es

(1) Cfr: FOCAULT, M. 1976, pág. 82 y ss.; BUSTOS RAMIREZ, J. 1982, pág. 118 y ss. ; BECCARIA, C. 1974, pág. 71-79. 
decir, como un enunciado que orienta y limita las decisiones del Estado. En nuestro caso las decisiones del Control Penal.

Todas estas políticas tienen una misma función: orientar al legislador hacia la construcción de un sistema de Control Penal respetuoso de los derechos humanos y que busque la solución de los conflictos sociales en vías alternativas al uso de la pena. Es decir, que ellos son la base para la existencia de un derecho penal mínimo y garantista.

Nuestra Constitución en sus artículos 1, 2, 232, 233, 234 y. 235 incorpora la mayoría de los principios a que hacemos referencia. Otros en cambio son recibidos de modo indirecto. Esto ocurre con los principios reconocidos en los artículos 4, 5, 7, 8 y 9 de la Convención Americana sobre Derechos Humanos, así como los recogidos en los numerales $6,7,9,10,14$ y 15 del Pacto Internacional de Derechos Civiles y Políticos. Como lo menciona expresamente la decimosexta de las Disposiciones Generales y Transitorias de la Carta de 1979, tales instrumentos internacionales también forman parte de nuestro sistema legal. Naturalmente, otra cosa es que la legislación penal adopte y aplique, realmente, esas premisas constitucionales de control. Sin embargo, es de reconocer que los proyectos de código penal de 1985 (Título Preliminar) han consagrado los principios penales de modo expreso e integral).

Fundamentalmente todos estos principios afectan las decisiones de criminalización ( $P$. Legalidad, Bien Jurídico Real y Mínima Intervención) y de definición y aplicación de sanciones (P. Humanidad, Culpabilidad, Jurisdiccionalidad y Proporcionalidad ).

A continuación desarrollaremos brevemente los contenidos formales y materiales de cada uno de ellos (2).

(2) Cfr. MAYER, D. 1987, pág. 53-58; VASSALLI, G. 1987, pág. 73-86: PETTITI, L.E., 1987 , pág. 167-181; BRAMONT ARIAS, L. 1988, pág. 9; BARATTA, A. 1987, pág. 91 y ss.; VELASQUEZ, F. 1989, pág. 13 y ss. 


\section{Principio de Legalidad}

En un sentido formal enuncia que sólo la ley puede señalar qué conductas son delictivas y cuáles son las penas que se pueden imponer a tales actos ilícitos.

Asimismo, este principio dispone que sólo puede sancionarse como autor de delito, a quien realizó un acto que previamente la ley, de modo inequívoco, había calificado como delictivo.

Como consecuencia de estas premisas formales del principio de legalidad, derivan las siguientes reglas:

a. La prohibición de aplicar la analogía para suplir vacíos del derecho penal, salvo el caso de la "analogía en bona partem" y siempre en favor del procesado o condenado.

b. La irretroactividad de la ley penal en cuanto sea desfavorable al procesado o condenado.

Ahora bien, en su acepción material el principio de legalidad es una garantía de la libertad personal y política de los ciudadanos. El se constituye en un límite jurídico importante para todo acto de poder estatal. Por consiguiente la ley penal debe ser clara y precisa. A través de ella se debe percibir e inferir el ámbito de ejercicio de la libertad ciudadana que es limitado en favor de la convivencia. Pero además la certeza legal acerca de lo delictivo, posibilita impedir toda arbitrariedad o abuso de parte de quien ostenta el poder.

Lamentablemente la legislación peruana, como ya habíamos insinuado, se caracteriza por su escaso respeto hacia el principio de legalidad. Lo cual es mucho más evidente cuando se analizan las cuotas de certeza, que de lo ilícito nos brinda el legislad or en las normas penales. Un ejemplo bastante elocuente al respecto se encontraba en el art. 185, inc. b del Código Sa nitario. Según dicho dispositivo constituía delito contra la salud, sancionable con hasta 20 años de prisión, "La violación consciente de la norma de salud". 
Pero, ¿cuál era la norma de salud? ¿Cómo evitar entonces su violación? Nada de ello se mencionaba en el citado artículo del Código Sanitario. La inseguridad jurídica y las oportunidades para la arbitrariedad del Control son, pues, peligrosamente potenciadas con disposiciones penales de tales caracteristicas. En otros casos la vaguedad del lenguaje empleado en la redacción de los tipos penales, conduce a defectos y riesgos similares. Al respecto, el artículo 1 del Decreto Legislativo 46, y el artículo 288-A del Código Penal, constituyen también un serio atentado al principio de legalidad por su escasa claridad (3).

El principio de legalidad está reconocido constitucionalmente por los párrafos "a", "b" y "d" del inciso 20 del artículo 2; inciso $8 \mathrm{del}$ artículo 233 ; y párrafo segundo ab initio del artículo 187 de la Constitución. Los artículos 2 y 3 del Código Penal también lo consagran de modo explícito dentro de las "Garantías de la Ley Penal".

\section{Principio del Bien Juridico Real}

Este principio es desde hace algún tiempo, la política más útil e importante para poner límites democráticos al jus puniendi.

Según su enunciado central, el bien jurídico real pretende que toda decisión política de criminalización primaria - crear un delito- sea el resultado de la necesidad de tutelar un determinado interés individual o colectivo de trascendencia social. Por consiguiente, es arbitrario incriminar conductas sólo para promover o reforzar ideas, credos o intereses particulares de grupos minoritarios. Y tampoco pueden considerarse como bienes jurídicos nociones abstractas o eminentemente valorativas. Este es el caso por ejemplo de conceptos como "buenas costumbres". Se podrá proteger la libertad de autodeterminación sexual, que si es un interés necesario para la vida social, pero no una "costumbre sexual" (4).

(3) Cfr. HURT ADO, J. 1987, pág. 154 y ss.

(4) Cfr. PRADO S. V. 1985, pág. 255 y ss. 
El bien jurídico real es también un principio que posibilita una crítica penal permanente. A través de él, como propone Bustos, es posible discutir el por qué de la protección penal. O más aún, evaluar la razón de Estado que determina la intervención del control penal en un ámbito concreto de las relaciones sociales (5). Y para ambos cometidos el bien jurídico real a través de su exigencia de lesividad, se constituye también en un instrumento oportuno y adecuado que denuncia todo exceso criminalizador del Poder (6).

En el Perú, por ejemplo, el rol crítico del Principio de Bien Jurídico Real ha permitido demitificar múltiples "decisiones penales" del Estado. Verbigracia, a través de él se ha podido reconocer que la criminalización de actos de rechazo a la reforma agraria, sólo perseguía la potenciación aplicativa de una política de desarrollo. Y que detrás de la penalización de la huelga de hambre no existía un propósito de proteger la salud, sino un afán autoritario de superar con la represión penal las paralizaciones y demandas sindicales.

Ahora bien, pese a no sostener una posición jurídico-constitucionalista frente al bien jurídico, consideramos que la Constitución aparece como el marco más adecuado y seguro para la identificación social de bienes jurídicos. Basta con señalar que en ella se reproducen la mayoría de derechos individuales y colectivos que por su trascendencia para la interacción social, cumplen con los requisitos que demanda todo objeto de protección penal.

\section{Principio de Minima Intervención}

Muy ligado a las ideas de libertad individual y de materialidad del interés tutelado por la ley penal, ambas emergentes de los principios de legalidad y de bien jurídico real, encontramos al Principio de Mínima Intervención.

(5) Cfr. BUSTOS RAMIREZ, J. 1984, pág. 50 y ss.; 1986, pág. 27 y ss.

(6) Cfr. VIVES ANTON, T. 1977, pág. 90 y 91; COBO DEL ROSAL, M. y VIVES ANTON, T. 1984, pág. 273 y ss.; MUÑOZ CONDE, F. 1975, pág. 49 y ss. 
Mediante esta política se demanda que el Estado sólo interfiera en la libertad ciudadana, cuando sea necesario proteger un bien jurídico. Pero, además, este principio señala que toda intervención penal del Estado sólo debe operar cuando hayan fracasado otras medidas también útiles para tutelar el bien jurídico. Por tanto, pues, deben agotarse todos los controles extra penales. A esta consecuencia de la política de mínima intervención se le denomina también principio de Derecho Penal última ratio.

En nuestro país este principio es permanentemente ignorado por el legislador. Para él todo problema criminal debe ser afectado exclusivamente desde el control penal. El derecho penal es más bien la única ratio. La criminalización de actos contra el eco sistema en el proyecto de código penal de 1986 y en el proyecto de código del medio ambiente, son lógicas consecuencias de dicha praxis (7). Es indudable que una tutela eficaz del ambiente dependerá más de un buen orden o control administrativos, que de normas punitivas de dudosa efectividad social.

Ahora bien, los desenlaces técnicos de una política penal que ignora al Principio de Mínima Intervención son negativamente evidentes en nuestra legislación penal. Por ejemplo los casos de duplicidad de tipos legales o la innecesaria "especialización" de objetos de acción típica suelen ser frecuentes. Esto último puede observarse en la ley 24991 que sin necesidad tipifica dentro del artículo 237 del código penal el hurto de semovientes. Y en el decreto legislativo 469 que "amplió" desde la legislación bancaria, los al-. cances de los delitos de defraudación y falsificación de documentos.

\section{Principio de Humanidad}

E1 Principio de Humanidad sostiene que el control penal no puede aplicar ni establecer sanciones que afecten la dignidad de la

(7) Cfr. artículos 263 a 270 del Proyecto de Código Penal de 1986, y artículos 296 a 303 del anteproyecto de Código de Protección del Ambiente de 1984. Véase también MARTOS NUÑEZ J. A. 1987, pág. 100 y ss. 
persona, ni que dañen la constitución psicofísica de los condenados. Por tanto, mucho menos se pueden incluir penas que destruyan la vida de las personas.

Asimismo, este principio demanda que los centros de reclusión y detención así como el procesamiento no constituyan riesgos de deterioro o de lesión al detenido. Que se erradiquen las torturas o las desapariciones y ajusticiamientos extra judiciales, como medios informales de control penal.

Junto con el Principio de Legalidad, la política de humanidad del control fue un importante aporte del liberalismo.

Materialmente, el Principio de Humanidad es un límite a las penas de muerte y de prisión indeterminada. Asimismo, impone al Estado la obligación de esforzarse por dotar a su infraestructura carcelaria de los medios y recursos que impidan que el interno sufra vejámenes y que se desocialice. Por último, que en los interrogatorios policiales la tortura y el maltrato no sean una técnica cotidiana de arrancar confesiones.

Esta política además obliga al Estado a sensibilizar social y cívicamente a sus órganos de control, fundamentalmente a la policía y a la administración penitenciaria.

Está claro que en nuestro país y en la concreta coyuntura que hoy vivimos, la política de humanidad del control no es acatada. Por ejemplo, el secuestro puede ser reprimido con pena de internamiento perpetuo. Aún existe la pena de muerte. Las cárceles son centros de desocialización y de exterminio. Los detenidos por delitos de terrorismo suelen ser objeto de torturas. Y las fuerzas de intervención en las zonas de emergencia son acusadas permanentemente de realizar desapariciones y aplicar ejecuciones extrajudiciales.

El Principio de Humanidad es reconocid o formalmente en los párrafos $\mathrm{h}, \mathrm{j}$, i del inciso $20 \mathrm{del}$ art. 2 ; incisos 12 y $19 \mathrm{del}$ artículo 233; y el art. 234 de la Constitución. 
Asimismo, él se refleja en el Título Preliminar y en el Título I del Código de Ejecución Penal.

\section{Principio de Culpabilidad}

La culpabilidad como categoría sistemática del delito se encuentra desde hace algunos años en crisis. Es más, en el presente no son pocos los autores que ya no operan dogmáticamente con ella, o que vienen aplicando conceptos alternativos (8).

Ahora bien, al margen de las críticas que se formulan al libre albedrío como base de la culpabilidad, y de las nuevas fórmulas y funciones sustitutivas que se postulan en la doctrina, existe todavía acuerdo en reconocer al Principio de Culpabilidad un rol garantista importante (9). Por tanto, pues, él sigue siendo una base útil para la construcción de un derecho penal coherente con los postulados de un Estado Social y Democrático de Derecho (10).

Concretamente, el Principio de Culpabilidad senala que no hay pena sin culpabilidad. De este enunciado se derivan tres consecuencias materiales:

a. Que no hay responsabilidad objetiva o por el mero resultado.

b. Que la responsabilidad es por el acto y no por el autor.

c. Que la culpabilidad es la medida de la pena.

Según Roxin la pena puede aplicarse por debajo de la culpabilidad si así aconsejan razones de prevención especial (11). No

(8) Cfr. GIMBERNAT ORDEIG, E. 1981, pág. 118 y ss.; ROXIN, C. 1981, pág. 57 y ss.; BUSTOS RAMIREZ, J. 1984, pág. 365 y ss.; STRATENWERTH, G. 1980, pág. 90 y ss.; JAKOBS, G. 1983, pág. 392 y ss.

(9) Cfr. BACIGAluPO, E. 1982, pág. 247 y ss.; ROXIN, C. ob. cit. pág. 42 y ss.; STRATENWERTH, G. ob. cit. pág. 109 y ss.

(10) Cfr. MIR PUIG, S. 1985, pág. 79 y ss.

(11) Cfr. ROXIN, C. ob. cit. pág. 103 y ss. 
obstante, cabe reconocer que tal afirmación es válida para justificar supuestos de atenuación más o menos tradicionales (imputabilidad restringida, etc.). En ningún caso se puede utilizar dicho criterio para legitimar las atenuantes e impunidades que surgen de aplicar el llamado "derecho penal premial". Fundamentalmente porque tales medidas afectan los cauces ordinarios y garantías del proceso penal. La reciente ley 25103 constituye, pues, una seria contradicción al sentido limitad or del Principio de Culpabilidad.

En el Perú el principio que comentamos ha sido permanentemente afectado. Los casos de represión objetiva han sido sumamente frecuentes en nuestra legislación penal. A modo de ejemplo podemos citar los decretos leyes 17388 y 19910.

El Principio de Culpabilidad se encuentra implícito en el artículo 2, inciso 20:f de la Constitución; en los artículos 1 y 167 del Código Penal; y en el artículo 284 del Código de Procedimientos Penales.

\section{Principio de Jurisdiccionalidad}

Por este principio se consagra la exclusividad del Poder Judicial para condenar e imponer sanciones a los autores o partícipes de un delito. Asimismo, de él derivan las principales garantías procesales: doble instancia, juez natural, debido proceso, publicidad del juicio, etc.

Nuestro sistema jurídico reconoce al Principio de Jurisdiccionalidad en los artículos 232 y 233 incisos $1,2,9,14$ y 18 de la Constitución. También se refieren a él los artículos 1,3 y 4 de la L.O.P.J. y el numeral 164 del Código Tributario.

El efecto material de este principio es que no pueden establecerse en el país tribunales paralelos a la justicia ordinaria penal, para avocarse al juzgamiento de delitos comunes. No obstante, en el pasado han sido frecuentes los tribunales especiales para juzgar determinados delitos. Basta con recordar al Consejo Nacional Ejecutivo contra el Tráfico de Estupefacientes creado por el decreto-lev 11005. 
En otros casos el Principio de Jurisdiccionalidad ha sido trasgredido a través del sometimiento de civiles al Fuero Castrense. Prototipo de ello fue el decreto-ley 17716 (octava disposición especial).

Ahora bien, en la actualidad el principio que analizamos es restringido en sus efectos por la aplicación de la ley 24150 . Esta ley, que regula la intervención de las Fuerzas Armadas y Fuerzas Policiales en las zonas de emergencia, ha motivado interpretaciones contradictorias sobre la competencia judicial en los delitos comunes, cometidos por militares o policías en agravio de civiles.

Infortunadamente, la Corte Suprema ha reconocido en algunos casos facultad jurisdiccional al Fuero Militar. Lo cual contradice abiertamente el claro sentido del artículo 324 del Código de Justicia Militar. Según esta disposición la Justicia castrense sólo puede juzgar delitos comunes cuando tanto el autor como la víctima tienen la condición de militares.

Esta equivocada tendencia del Tribunal Supremo ha originado que en la doctrina jurídico-militar se entienda que en las zonas de emergencia la Justicia ordinaria no tiene atribuciones. Así por ejemplo lo expresan Temple y Avalos: "Los casos de intervención de personal militar o policial en cumplimiento o con ocasión de la misión asignada durante la vigencia de los Estados de Excepción declarados en una zona determinada, y que tengan como resultado lesiones o muerte de civiles, los presuntos delitos o responsabilidades son de exclusiva competencia del Fuero Privativo Militar. Las autoridades judiciales del fuero Ordinario, no tienen atribuciones para intervenir, por encontrarse en suspenso su jurisdicción y' competencia" (12).

Es menester, pues, recuperar el espacio perdido por la justicia ordinaria en las zonas de conflicto. No hacerlo implica renunciar al Principio de Jurisdiccionalidad y dejar al ciudadano en si-

(12) TEMPLE DE LA PIEDRA, L. y AVAlos ZELASCO, A. 1988, pág. 185 . 
tuación de indefensión frente a la arbitrariedad. Por consiguiente, pues, urge modificar y hacer más explícitos los alcances de la Ley 24150 (13).

\section{Principio de Proporcionalidad de las Sanciones}

De origen retribucionista, esta política demanda que la sanción debe guardar relación con el daño ocasionado y con el bien jurídico protegido. Por consiguiente, la aplicación de sanciones debe ser proporcional al delito y a las circunstancias de su comisión. Lo cual relaciona de modo directo a este principio con el de culpabilidad (14).

Del Principio de Proporcionalidad se desprende que todo uso desmedido de las sanciones, sean penas o medidas de seguridad, representa una restricción o privación de derechos abusiva. De él también deriva la necesidad de establecer límites claros y tolerables a cada pena.

Nuestro sistema punitivo ha demostrado en los últimos 50 años una vocación draconiana y de simbolismo preventivo-general. La pena, pues, ha sido fundamentalmente un medio emocional de apaciguamiento $y$ de terror sociales. Un buen ejemplo de esta tendencia es lo ocurrido con el delito de secuestro extorsivo. Frente al incremento de este tipo de infracciones, el legislador modificó el artículo 223 del Código Penal, estableciendo pena de internamiento para dicho delito. Con esta decisión se colocaba al secuestro extorsivo a la altura del asesinato. Se quebraba pues la proporcionalidad en razón de los bienes juridicos tutelados. De otro lado, la seguridad de la víctima era disminuida notablemente, pues su muerte a manos del secuestrador no representaba una pena mayor (15).

(13) Cfr. BERNALES, E. Recomendaciones Generales. 1988, pág. 12 y ss.

(14) Cfr. MIR PUIG, S. ob. cit. pág. 83 y ss.; STRATENWERTH, G. ob. cit. pág. 71 y ss.

(15) PRADO, V. Debate Penal No. 1, 1987, pág. 66 y ss. 
El Principio de Proporcionalidad no está regulado de modo expreso en nuestra legislación. Sin embargo, su aceptación como política reguladora del control surge del artículo 4 de la Constitución y de la aplicación sobria de los artículos 50 y 51 del Código Penal. 


\section{BIBLIOGRAFIA CITADA}

1. BACIGALUPO, E.

¿Tienen Rango Constitucional las consecuencias del Principio de Culpabilidad?. En:Derecho Penal y Criminología, No. 18, 1982.

2. BARATTA, $A$.

Requisitos mínimos del respeto de los derechos humanos en la ley penal. En:Derecho Penal y' Criminología, No. 31, 1987.

3. BECCARIA, C.

De los delitos y de las penas. Ed. Aguilar. Madrid, 1974.

4. BERNALES BALLESTEROS, E.

Violencia y Pacificación. Recomendaciones Generales. Senado de la República. Lima, 1988.

5. BRAMONT ARIAS, L.

La Nueva Constitución y los Principios Penales. En Temas de Derecho Penal, Tomo 1. SP Editores. Lima, 1988.

6. BUSTOS RAMIREZ, J.

Introducción al Derecho Penal. Ed. Temis. Bogotá. 1986.

7. BUSTOS RAMIREZ, J.

Manual de Derecho Penal. Parte General. Ariel Barcelona, 1984.

8. BUSTOS RAMIREZ, J.

Bases Criticas de un nuevo Derecho Penal. Ed. Temis. Bogotá, 1982.

9. COBO DEL ROSAL, M. y VIVES ANTON, T.S.

Derecho Penal. Parte General. U. de Valencia. Valencia, 1984. 
10. FOCAULT, $M$.

Vigilar y Castigar: Nacimiento de la prisión. Ed. Siglo XXI. México, 1976.

11. GIMBERNAT ORDEIG, E.

Estudios de Derecho Penal, 2a. Ed., Ed. Civitas. Madrid, 1981.

12. HURTADO POZO,J.

Manual de Derecho Penal. Parte General, 2a. Ed. EDDILI. Lima, 1987.

13. JAKOBS, G.

Strafrecht. Allgemeiner Teil. Die Grundlagen und die Zurechnungslehre. Lehrbuch Walter de Gruyter. Berlin-New York, 1983.

14. MAYER, D.

Principes Constitutionnels et principes géneraux applocables en droit pénal fraçais, En: Revue de Science Criminelle et de droit pénal comparé, No. 1, 1987.

15. MARTOS NUÑEZ, J.A.

El Principio de Intervención Penal Minima. En: Anuario de Derecho Penal y Ciencias Penales. Fascículo I, 1987.

16. MIR PUIG, $S$.

Derecho Penal. Parte General. 2a. Ed. PPU. Barcelona, 1985.

17. MUÑOZ CONDE, F.

Introducción al Derecho Penal. BOSCH. Barcelona, 1975.

18. PETTITI, L.E.

Les principes géneraux de droit pénal dans la Convention européenne des droits de l'homme, En: Revue de Science Criminelle et de droit pénal comparé, No. 1, 1987.

19. PRADO SALDARRIAGA, V.

Notas críticas a la politica criminal del gobierno "de todos los peruanos", En:Debate Penal. No. 1, 1987. 
20. PRADO SALDARRIAGA, $V$.

Política Criminal Peruana. Ed. Cuzco. Lima, 1985.

21. ROXIN, C.

Culpabilidad y Prevención en Derecho Penal. Ed. REUS. Madrid, 1981.

22. STRATENWERTH, G.

El Futuro del Principio Jurídico Penal de Culpabilidad. U. Complutense. Madrid, 1980.

23. TEMPLE DE LA PIEDRA, L. y AVALOS ZELASCO, A.

La Justicia Militar en Estado de Excepción, En Revista de Marina. Marzo-Abril, 1988.

24. VASALLI, G.

Le droit italien, principes géneraux applicables a la matiere pénale. En: Re'rue de Science Criminalle et de droit pénal comparí. No. 1, 1987.

25. VELASQUEZ VELASQUEZ, F.

Normas Rectoras del Proyecto de Código Penal Peruano de 1986. En: Amuario de Derecho Penal 88. Asociación Peruana de Derecho Penal. Lima, 1989.

26. VIVES ANTON, T.S.

Reforma Politica I. Derecho Penal. En: Cuadernos de Politica Criminal. No. 1, 1977. 